\title{
Presystolic mitral closure sound in aortic regurgitation with left ventricular hypertrophy and first degree heart block
}

\author{
THOMAS A TRAILL, NICHOLAS J FORTUIN \\ From Fohns Hopkins University, School of Medicine, Division of Cardiology, Baltimore, Maryland, USA
}

SUMMARY We report a patient who developed aortic regurgitation and first degree atrioventricular :block caused by infective endocarditis complicating aortic valve stenosis. There was premature $\infty$ closure of the mitral valve and, in the absence of an Austin Flint murmur, a simultaneous high 9 frequency sound was audible which we regard as a presystolic first heart sound. That such a sound may be associated with valve closure, even though this precedes electrical and mechanical ventricular systole, provides further support for the valvular origin of the first heart sound.

It is generally taught that the two components of the first heart sound are the result of closure of the mitral and tricuspid valves. An alternative mechanism has been proposed, however, which relates the audible sounds to left ventricular myocardial contraction and the onset of ejection. ${ }^{1}$ Because the events in question usually occur within a short time of one another, neither hypothesis has received conclusive support, so that circumstances in which atrioventricular valve closure is dissociated from the onset of ventricular systole might provide an opportunity to distinguish these possibilities. In cases of aortic regurgitation the left ventricular diastolic pressure may exceed the left atrial pressure so that the mitral valve closes before the onset of contraction. In such patients the sound which follows the QRS is soft, but a distinct premature mitral valve closing sound is not usually heard. We report a patient who had left ventricular hypertrophy, first degree atrioventricular block, and aortic regurgitation, in whom premature mitral valve closure was associated with an audible diastolic heart sound.

\section{Case report}

A 78-year-old black man was admitted for investigation of a cerebrovascular accident. Two years previously he had developed shortness of breath and angina pectoris, and was found to have aortic valve stenosis. He was treated with digoxin and diuretics which improved his symptoms. Two months before the present admission he began to feel generally unwell and developed anorexia, weight loss, nocturnal dyspnoea, and night sweats. The night before admission he experienced abrupt onset of right sided weakness and difficulty with speech.

There were signs of recent weight loss, a fever, and mild right sided spastic paresis. There were no peripheral stigmata of infective endocarditis. The heart rate was 84 per minute and blood pressure 110/ $60 \mathrm{mmHg}$. Peripheral pulses were of small volume and there was a carotid thrill. There were no signs of fluid retention. The cardiac impulse was felt in the sixth interspace at the anterior axillary line and was sustained. On auscultation both first and second heart sounds were soft. A loud ejection systolic murmur was heard at the base, and there was a soft early diastolic murmur. There were two added sounds in 은 diastole. The first of these was soft and of low $D$ frequency; this was followed by a second, louder, and of high frequency.

The electrocardiogram showed sinus rhythm with first degree atrioventricular block and left ventricular hypertrophy. The echocardiogram showed severe left $\mathrm{\omega}$ ventricular hypertrophy with reduced end-systolic and end-diastolic dimensions. There was premature $\theta$ closure of the mitral valve. Simultaneous recording of the apexcardiogram, phonocardiogram, and echocar- $\stackrel{\infty}{\rightarrow}$ diogram (Fig.) indicated that of the two added sounds $T$ in diastole, the first low frequency sound coincided with a combined rapid filling wave and a-wave of the $\stackrel{\square}{\stackrel{\circ}{\circ}}$ apical impulse, and thus represented a summation $\unrhd$ sound. The second high frequency one coincided with $\overline{2}$ presystolic mitral valve closure. 


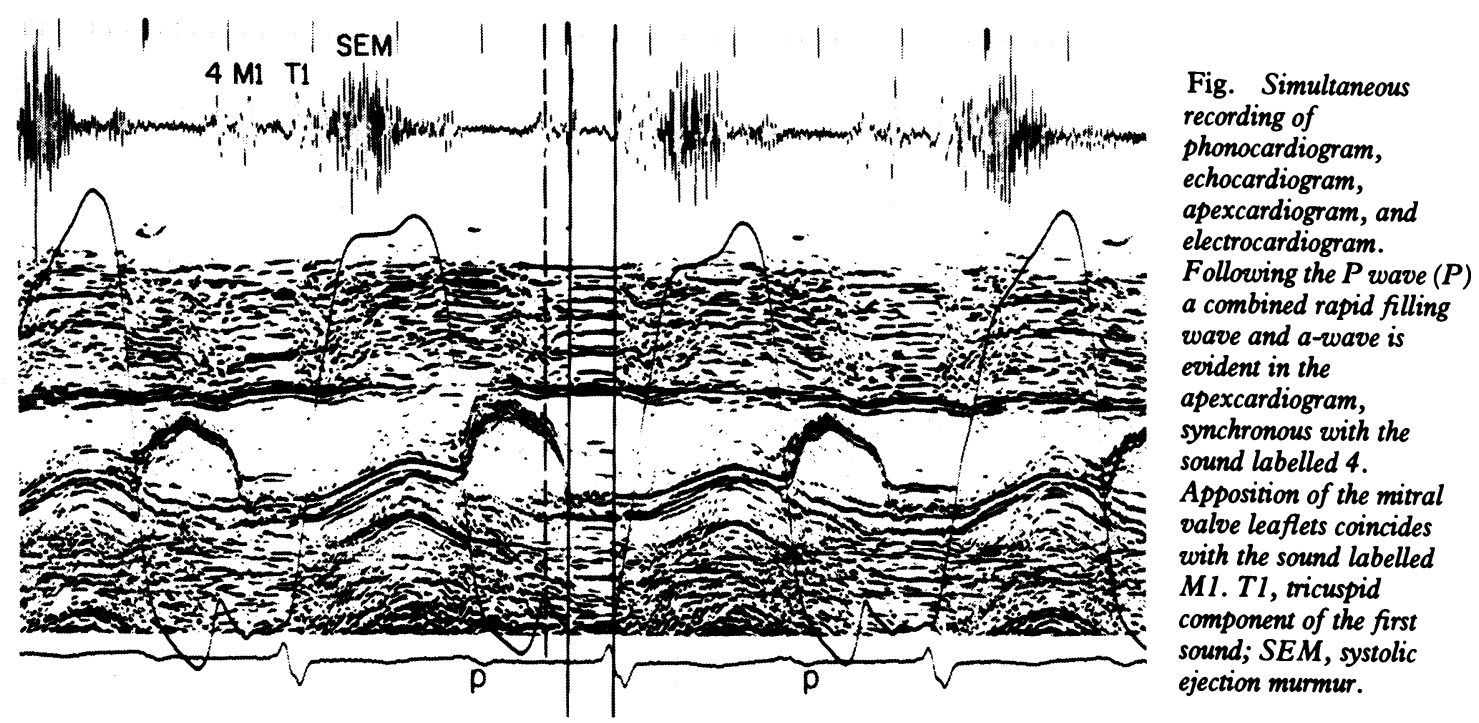

Blood cultures grew Strep. viridans and the patient was treated with a course of parenteral penicillin and gentamicin. His neurological changes improved and he was discharged after six weeks, taking digoxin and hydrochlorothiazide.

\section{Discussion}

The subject of the present report had left ventricular hypertrophy and first degree atrioventricular block together with aortic regurgitation which was of recent onset but not severe. The echocardiogram shows complete mid-diastolic closure of the mitral valve, which was accompanied by an easily audible high frequency sound. This followed by some $200 \mathrm{~ms}$ a low frequency sound which, from its relation to the combined rapid filling wave and a-wave of the apexcardiogram, we take to be a summation sound. Both the timing of these sounds, and their relative frequencies, make us conclude that the second is a true mitral closure sound and thus represents a presystolic "first heart sound". Following the onset of the QRS by 45 ms there occurred a further high frequency sound, which was not split, and which preceded the onset of ejection as evidenced by the carotid upstroke. This we take to represent the second component of the first heart sound, and presumably corresponds to tricuspid valve closure.

Premature closure of the mitral valve and the loud sound which accompanied it were probably the result of a combination of factors. In patients with acute or severe aortic regurgitation the mitral valve frequently closes before the onset of left ventricular systole. This was at first inferred from the observation of diastolic crossover of the left ventricular and left atrial pressures $^{2-5}$ and has since been confirmed by a number of echocardiographic studies. ${ }^{6-9}$ Such premature closure has been identified as part of the mechanism of the Austin Flint murmur. ${ }^{7}$ Though it has been noted that the first heart sound is attenuated in such patients, in only one report has mention been made of a diastolic sound and this was recorded with an intracardiac microphone. ${ }^{5}$ Meadows et al. ${ }^{10}$ considered the possibility that a mid-diastolic mitral valve closure sound in their patients might have been masked by the presence of an Austin Flint murmur. In uncomplicated first degree heart block, when the first heart sound is audible it follows the onset of ventricular systole. Its intensity appears to depend on the degree of separation of the mitral leaflets at enddiastole, in turn determined by the interval between the atrial and ventricular contributions to mitral valve closure. When apparent presystolic closure of the valve occurs, this is not usually audible or recordable. ${ }^{11}$ We speculate that in the present patient the simultaneous occurrence of rapid filling and atrial systole coupled with persisting retrograde filling of the ventricle caused an abrupt rise in ventricular diastolic pressure and sudden termination of forward flow across the mitral valve. The signs did not suggest that aortic regurgitation was itself of great severity and the patient did not require surgery, so that the rapid rise in ventricular diastolic pressure must be attributable more to its abnormal elasticity than to the magnitude of the diastolic volume load.

The arguments for the valvular hypothesis of the generation of the first heart sound are based for the most part on the simultaneous occurrence of the two 
components with the corresponding movements of the mitral and tricuspid valves, studied indirectly by manometry ${ }^{1}$ or more directly by echocardiography. ${ }^{12}$ Thus mitral valve closure has been shown to occur an appreciable interval after the crossover of left atrial and left ventricular pressures, and synchronous with the first component. ${ }^{13}$ Similarly, the second component precedes aortic valve opening, and is synchronous with tricuspid valve closure, a relation that persists when tricuspid closure is delayed. ${ }^{14}$ Further evidence for the valvular hypothesis is the finding that in atrioventricular block the intensity of the first sound varies according to the velocity of closure of the mitral valve leaflets. ${ }^{11}$ In all such studies, however, it is impossible to separate the timing of valve movements from the other mechanical events that characterise the onset of left ventricular systole, so that effects of the latter can never be completely discounted as contributing to the audible sound. The occurrence of premature mitral valve closure in cases of aortic regurgitation with high left ventricular diastolic pressure therefore provides an experiment of nature in which valve movements and ventricular systole are dissociated. Our finding that in this situation the first component of the first heart sound may also be dissociated from ventricular systole seems to us to lend further support to the valvular hypothesis.

\section{References}

1 Luisada AA, MacCanon DM, Kumar S, Feigen LP. Changing views on the mechanism of the first and second heart sounds. Am Heart f 1975; 88: 503-14.

2 Wright JL, Toscano-Barboza E, Brandenburg RO. Left ventricular and aortic pressure pulses in aortic valvular disease. Proceedings of the Staff Meeting of the Mayo Clinic 1956; 31: 120-6.

3 Colvez P, Alhomme P, Samson M, Guedon J. La pression de remplissage du ventricule gauche dans les grandes insuffisances aortiques: ses relations avec l'allongement de la conduction auriculo-ventriculaire. Arch Mal Coeur 1959; 52: 1369-73.

4 Kelly ER, Morrow AG, Braunwald E. Catheterization of $\overrightarrow{\vec{D}}$ the left side of the heart. $N$ Engl $\mathcal{Y}$ Med 1960; 262: 162-8.

5 Rees JR, Epstein EJ, Criley JM, Ross RS. Haemodynamic effects of severe aortic regurgitation. $\mathrm{Br}$ Heart $\mathcal{F}$ 1964; 26: 412-21.

6 Pridie RB, Benham R, Oakley CM. Echocardiography of the mitral valve in aortic valve disease. Br Heart $\mathcal{F}$ 1971; 年 33: 296-304

7 Fortuin NJ, Craige E. On the mechanism of the Austin $\vec{\circ}$ Flint murmur. Circulation 1972; 45: 558-70.

8 Botvinick EH, Schiller NB, Wickramasekaran R, $\vec{\omega}$ Klausner SC, Gertz E. Echocardiographic demonstration of early mitral valve closure in severe aortic insufficiency. Circulation 1975; 51: 836-47.

9 Mann T, McLaurin L, Grossman W, Craige E. Assess- ing the hemodynamic severity of acute aortic regurgita- $\infty$ tion due to infective endocarditis. $N$ Engl $\mathcal{F}$ Med 1975; 293: 108-13.

10 Meadows WR, Van Praagh S, Indreika M, Sharp JT. $\vec{c}$ Premature mitral valve closure: a hemodynamic explanation for absence of the first sound in aortic insufficiency. Circulation 1963; 28: 251-8.

11 Burggraf GW, Craige E. The first heart sound in com- N plete heart block. Circulation 1974; 50: 17-24.

12 Craige E. On the genesis of heart sounds. Circulation 1976; 53: 207-9.

13 Mills PG, Chamusco RF, Moos S, Craige E. Echophonocardiographic studies of the contribution of the atrioventricular valves to the first heart sound. Circulation 1976; 54: 944-51.

14 Waider W, Craige E. First heart sound and ejection sounds: echocardiographic and phonocardiographic correlation with valvular events. Am $\mathcal{f}$ Cardiol 1975; 35: 346-56.

Requests for reprints to $\mathrm{Dr}$ Thomas A Traill, The Johns Hopkins Hospital, $600 \mathrm{~N}$ Wolfe Street, Baltimore, Maryland 21205, USA. 